\title{
COOLANT MIXING IN LMFBR ROD BUNDLES AND OUTLET PLENUM MIXING TRANSIENTS
}

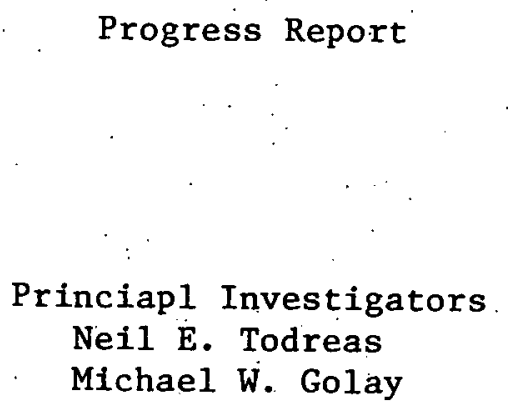

Progress Report

Massachusetts Institute of Technology

Department of Nuclear Engineering Cambridge, Massachusetts 02139
This NOPOTICE

This report was prepared as an account of work sponsored by the United States Government. Neither Research and States nor the United States Energy Research and Development Administration, nor any of their employees, nor any of their contractors, subcontractors, or their employees, makes warranty, express or implied, or assumes any legal liability or responsibility for the accuracy, completeness or usefulness of any information, apparatus, product or process disclosed, or represents that its use would not infringe privately owned rights.

\footnotetext{
December 1, 1974 - February 28, 1975

Prepared for the U.S. Energy Research and Development Administration under Contract No. AT(11-1)-2245
} 


\section{DISCLAIMER}

This report was prepared as an account of work sponsored by an agency of the United States Government. Neither the United States Government nor any agency Thereof, nor any of their employees, makes any warranty, express or implied, or assumes any legal liability or responsibility for the accuracy, completeness, or usefulness of any information, apparatus, product, or process disclosed, or represents that its use would not infringe privately owned rights. Reference herein to any specific commercial product, process, or service by trade name, trademark, manufacturer, or otherwise does not necessarily constitute or imply its endorsement, recommendation, or favoring by the United States Government or any agency thereof. The views and opinions of authors expressed herein do not necessarily state or reflect those of the United States Government or any agency thereof. 


\section{DISCLAIMER}

Portions of this document may be illegible in electronic image products. Images are produced from the best available original document. 
Reports Isslied Under this Contract.

A. Quarterly Progress Reports

\begin{tabular}{|c|c|}
\hline $00-2245-1$ & Period June 1, 1972 - November 30, 1972 \\
\hline $000-2245-2$ & Period December 1, 1972 - February 28, 1973 \\
\hline $\operatorname{coo}-2245-3$ & Period March 1, 1973 - May 31, 1973 \\
\hline $\cos -2245-6$ & Period June 1, 1973 - August 31, 1973 \\
\hline $\cos -2245-7$ & Feriod September 1, 1973 - November 30,1973 \\
\hline$c 00-2245-8$ & Period December 1, 1973 - February 28, 1974 \\
\hline $000-2245-10$ & Period llarch I, 2974 - May 31, 1974 \\
\hline coo-2245-13. & Period June 1, 1974 - August 31, 1974 \\
\hline $\operatorname{coo}-2245-14$ & Perlod September 1, 1974 - November 31, \\
\hline coo-2245-15 & Period December 1, 1974 - February 28, \\
\hline
\end{tabular}

B. Toplcal Peports

E. Khan and N. Todreas, "A Review of Recent Analytical and Experimental Studies Applicable to IMFBR Fuel and Blanket Assembly Design," COO-2245-4TR, UIT, Sept. 1973.

E. Khan, W. Rohsenow, A. Sonin and N. Todreas, "A Simolified Approach for Fred1sting Temperature Distirbution in Wire Wrapped Assemblies," COO-2245-5TR, MIT, Sept. 1973

T. Eaton and N. Todreas, "Instrumentation Methods for Interchannel Coolant lixing Studies in Wire-Wrap Spaced Nuclear FueI Assemblies," Coo-2245-9'RR, MII, June 1974.

Y.B. Cnen, K. Ip, N.E. Todreas, "Velocity Measurements in Edge Subchannels of Wire Vrapped LilFBR Fuel Assemblies," Co0-2245-11Ti, iiIT, Sept. 1974 .

E. Khan, N. Todreas, W. Rohsenow, A.A. Sonin, "Anaiysts of Mixing Data Relevart to Wre-Wrapped Fuel Assembly ThermaiHydraul1c Design," CoO-2245-laTR, MIT, Sept. 1974. 
COOLANT MIXING IN LMFBR ROD BUNDLES AND OUTLET PLENUM MIXING TRANSIENTS

Contract AT(11-1)-2245

Quarterly Progress Report

December I, 1974 - February 28, 1975

The work of this contract has been divided into the following Tasks:

TASK I: BUNDLE GEOMETRY (WRAPPED AND BARE RODS)

TASK IA: Assessment of Avaliable Data

TASK IB: Experimental Bundle water Mixing

Investigation

TASK IC: Experimental Bundie Peripheral Velocity Measurements (Laser Anemometer)

TASK ID: Analytic Model Development - Bunäles

TASK II: SUBCHANNEL GEOMETRY (BARE RODS)

TASK IIA: Assessment of Avallable Data

TASK IIB: Experimental Subchannel Water Mixing Investigation

TASK IIC: Experimental Subchannel Local Parameter Measurements (Laser Anemometer)

TASK IID: Analytic Model Development - Subchannels

TASK III: LMFBR OUTLET PLENUM FLOW MIXING

TASK IIIA: Analytical and Experimental Investigation of Velocity and Temperature Fields 
TASK I: BUNDLE GEOMETRY (WRAPPED AND BARE RODS)

TASK IA: Assessment of Available Data (Ehsan Knani)

Efforts in this area ane reported under Task ID for this period.

TASK IB: Experimental Bundia Water Mixing Investigation

1) 61-Pin Fuel Experiment (Alan Hanson)

During this quarter work was completed on the coljection of data from the first 61-pin fuel bundle which has a 6-inch wire-wran lead length. Extensive pressure measurements were mace in addition to mixing experiments. Figure I shows the location of the four pressure taps drilled in the metal flow housing walls at each of two axial locations. The axial levels chosen were exactly two feet apart. An exact multiple of the vire-wrap pitch was chosen to eliminate the effects of local pressure variation and dynamic effects when the pressures at the two levels were subtracted -- the need for the careful spacing was confirmed by the data obtained. The wall taps were placed in the center of each face where they are opposite a rod instead of a flow channel, since this location was expected to have flow parallel to the face. The wall taps at each level were manifolded in such a way that the pressure on an individual face could be measured or any combination of tine four faces could be averaged: In addition, pressure differences between the faces at a given level could be measured. lo obtain axial pressure gradients, the average pressue or all four tapped faces was measureci at each level at high flowrates using absolute pressure gages; at low flowrates the pressure drop between two levels was measured directly using a dual-bellows differential pressure gage. Axial pressure gradients were reduced to friction factors based on an assumed flow split described by Novendstern [1]. The dependence of friction factor on Reynolds number is shown in Figure 2 . The experimental data exhibit several interesting characterisitcs:

(a) The data Iie in general above Novendstern's correlation but within the $14 \%$ error sand he suggests for the correlation.

(b) The apparent slope of the data in the turbulent range, 3000-30,000 Reynolds number, is steeper than both the smooth tube correlation and Novendstern's correlation.

(c) There seems to be no distinct laminar-turbulent transition as in smooth tube flow. Instead the data gradually approach both the turoulent and laminar Iine asymptoticaiiy. This benavior has also been observed by Fiehme [2]. 
Pressure difference across the flats of the hexagonal flow housing were measured directly using the differential pressure gage and found to be quite large. Figure 3 shows these pressure differences as a function of the bundle flowrate. Note that this radial pressure difference exhloits an approximately second order dependence on bundle flowrate as does the axial presure. gradient. In fact the ratio of the radial pressure drop to the axial pressure gradient seems to be a constant. For example, the pressure drop from face $C$ to face $F$ is roughly $47 \%$ of the axial pressure drop per wire-wrap pitch over the range of flows in Figure 3 .

The most interesting pressure data was obtained by the novel technique of using the salt injection rods as axially traversing pressure taps. The Injection rods are ideal for this purpose since they have a small opening, can travel over about 26 inches axially, and are easily disconnected from the salt injection system and connected to the differential pressure gage. By moving the injector rod up in 1/2-inch increments, It is possible to see the axial development of the local static pressure. Figure 4 shows this development for an edge subchannel at two different flowrates. It is clear from this figure that the axial pressure gradient is highly non-uniform and periodic with the same period as the wire-wrap pitch. The deviation of the local pressure gradient from the average Eradient (shown as a dashed line in Figure 4 ) is substantial. Similar data was taken for a centrally-located interior subchannel; although this data also showed some periodicity, the deviations from the average gradient were very small relative to those observed in the edge channel.

A complete set of salt tracer mixing experiments was also run on the 6-inch lead bundle. The series of four runs which were made are listed in Table 1 ; this series was cone for both an eage channel injection and for an interior channel injection. The first two runs are to demonstrate the axial development or the salt distribution in Iaminar and turbulent flow regimes. The next two runs are usea to determine if there is any effect of Reynolds number on the mixing. Data from these experiments are currently being aralyzed and will be reported next quarter.

Work on the data reauction code was continued and largely completed this quarter. The availability of large quantities of experimental data made posslble the testing of the cose in its entirety. Calibration and mass balance routines were found to function we 11 as expected. New plotting rolitines were added to facilitate data analysis. The following plots can now be generated of'fline on a CALCOMP plotter: 
(a) Mass balance vs. axial injection location

(b) Subchannel salt concentrations vs. circumferential channel location at a given axiai location.

In addition online plots of the plana salt distribution for a given axial injector location can be produced. Some minor refinements to the data reduction code still are necessary and will be carried out in the next quarter.

In addition to analysis of the 6-1nch data and code refinements already mentioned, work during the next quarter will include installation and experimentation with the 12-inch lead bundle to delineate the effect of wire-wrap lead on pressure fields and mixing.

\section{2) 61-Pin Blanket Experiments (Carl Oosterman)}

During the quarter construction of all experimental apparatus was completed. Probe construction is shown in Figure 5. The soldered connection between the platinum wire and the lead wire was coated with epoxy and covered with heat shrinkable insulation after assembly the probe tube was backfilled with polyurethane plastic. The insulation and polyurethane will minlmize the possibility of leakage which could short the leads. The probe and upper rod support system is shown in Figure 5 . The rubber gland was included to ensure probe positionirg would be unaffected by vibration.

The salt injector scheme described in the previous quarteriy report was usccessfuliy constructed with $30^{\circ}$ injection holes. The injector operated perfectly when tested.

The blanket bundle has been completely assembled in a dry run and no problems were encountered. The flow housing has been leak rested without the fuel rods and found tight. The conductivity probes are in the process of veing tested for short circuits. Once this is complete the probes can be platinized and the whole bundie assembled in the flow loop. At present both test positions in the flow loop are beling utilized. Experiments vill vegin as soon as one of the positions ofen, hopefully before the end of ilarch. 
TASK IC: Experimental Bundle Peripheral Velocity Measurements (Laser Anemometer) (Richard Anoba)

Due to the unavailability of the hydraulic facility associated with the 61-pin blanket bundle, perlpheral velocity measurements were not intiated during this quarter. Present estimates show that the hydraulic facilty should be available by early April.

During this period, the following tasks were accomplished:

(1) The procedure developed by Carajilescov for crosspoint allgnment of four laser beams with traverse frequency shift using the differential operational mode was exercised.

(2) Positions errors of the laser beam cross-point were determined due to:

(a) Optical unit/test section misalignment

(b) Optical bench/test section misalignment.

\section{Task (1)}

In this task, four laser beams were produced using two optical units in parallel. A single beam from the laser unit was split into two beams by way of an external beam splitter with supplementary external mirrors (see Fig. 7). Each of the resulting two beams was directed to an optical unit in order to be split into two additional beams (see Fig. 8). Hence, using two optical units, four beams were able to be produced in which the plane formed by one pair of beams was mutually perpendicular to the plane of the other pair of beams. This would potentialiy enable direct sequential (point-wise) velocity measurements in two mutualiy perpendicular directions under the condition that all four beams cross at the same measuring point. Since it is anticipated that the traverse velocity component would be relatively small compared to the axial velocity component, and more likely to be subject to $180^{\circ}$ directional ambiguity in flow measurements (reverse flow), the frequency unit was applied to the traverse beam pair. The physical effect of the frequency shift unit is to produce a deflected traverse beam pain in addition to the original (undeflected) traverse beam pair. (see Fig. 9).

The final step in the four beam alignment process was to align the cross-point of the axial beam pair to the deflected (or frequency sinifted) traverse beam pair. 
Task (2)

This task pertains to the determination of beam cross-point position errors due to optical unit/test section misalignment and optical bench/test section misalignment.

The model used to determine the position errors associated with optical unit/test section misalignment is shown in Fig. 10 The beam cross-point positions ( $x$ or $y$ ) plotted as a function of the misalignment angie $\gamma$, is shown in Figs. 11 \& 12 . (Note that characteristic measurement distances from the test section wall are used $\rightarrow$ approximately $0-40 \mathrm{mll}$ range for the blanket bundle.)

The model used to determine the position errors associated with optical bench/test section misalignment is shown in Fig. 13 . The beam cross-point position displacement ( $1 \Delta \times 1)$ plotted as a function of optical bench displacement ( $\Delta \mathrm{r}$ ) for various values of the misalignment arigle $\beta$, is shown in Figs. 14 and 15 . It should be noted that the position errors associated with optical unit/test section misalignment is less severe than the errors associated with optical vench/test section misalignment. However in both cases actual errors will be reduced in practice by realigning beams to one or more reference position in the bunde.

TASK ID: Analytical Methods Develópment

(a) Ehsan Khan

The analytic models developed include

$$
\begin{aligned}
& \text { ENERGY I - no capability for buoyant effects } \\
& \text { ENERGY II - buoyancy capability through friction } \\
& \text { and gravitational pressure losses in } \\
& \text { the axial momentum equation. } \\
& \text { ENERGY III - same as ENERGY II plus convective } \\
& \text { terms in axial momentum equation } \\
& \text { inciuded on same principles as } \\
& \text { the THINC-II }[2,3] \text { code. }
\end{aligned}
$$

During this period three topical reports have been prepared which 1) summarize the analytic model development performed to date, 2) present the three codes, and 3) present input data recommended for use in the three codes. These reports which will be issued next quarter are: 
1) E. Khan, W. Ro,hsenow, A. Sonin, N. Todreas

"A Porous Body Model for Predicting Temperature Distributions in Wire Wrapped Fuel and Blanket Assemblies of a LMFBR," COO-2245-16TR, MIT, March 1974.

2) E. Khan, W.M. Rohsenow, A.A. Sonin, N. Todreas, "Input Parameters to the ENERGY Code (to be used with the ENERGY Code Manual) COO-2245-17TR, MIT,

3) E. Khan, W. Rohsenow, A. Sonin, N. Todreas, "Manual for ENERGY. Codes I, II, III," COO-224518TR, MIT.

(b) Interassemb'ly Heat Transfer Study (Brian Chen)

The existing code, ENERGY, is capable of predicting the temperature distribution for a single assembly with insulated wall condition. By using the prediction of the ENERGY code for each individual assembly in a reactor core, it is not difficult to see that a moderate amount of heat transfer occurs between some nelghboring assemblies. In order to estimate these heat transfer effects, a parametric study has been done to estimate the percentage changes of the temperatures in an assembly due to this heat loss or heat gain. After normalizing the percentage change of the temperature by the ratio of the heat loss to the average heat generated within the assembly, we get a two-dimensional map for the temperature change which is independent of the assemblies. This assembly independent map would be very useful in judging whether the inclusion of the interassembly heat transfer would significantly change the temperature in the assembly.

When the inclusion of the interassembly heat transfers are important, a calculation procedure which includes these effects should be used. For this purpose we are preparing a new code capable of predicting the temperature distributicn for any combination of any rumber of fuel and blanket assemblies. Great progress has been achieved in preparing this new code. It is now capable of predicting any combination of any number of blanket assemblies. It has the option of predicting the temperature distribution for insulated assembly as weli as for interconnected assemblies with heat transfer between them. It has been structured to reoulre much less input data, better output format and more economical storage space than ENERGY-I. 
Future efforts will be on extending the code to include fuel assemblies and to do another interassembly parametric study with this new code.

A separate study was done to determine whether buoyancy effects are Important for the design conditions of the Clinch River Breeder Reactor. We found the buoyancy effects are not Important for all the assemblies in the core by comparing the calculated $\mathrm{G}$ : with $\mathrm{G}_{\mathrm{r}_{\mathrm{c}}}^{*}$

Based on this concludion thermal predictions of clinch River blanket assemblies were performed for WARD using ENERGY I. However, these predictions did not yet include the effect of interassembly heat. transfer.

(c) Generation of Input Data for Wire Wrapped Bundies (Frank Carré)

* The study consists of determining the three parameters $\left(\varepsilon_{H}^{*}, C l\right.$ and flow split) needed by ENERGY I and tries to match the theoretical results from this code with the experimentally measured temperatures in each of the following bundles:

-- ORNL bindle 5C (for low and high Reynolds numbers) Reference [3]

-W WI:I Scale test Reference [4]

-- Karlsruhe 61 pin bundle.

ORNL Bundle 5C

The paranieters $\varepsilon_{H}^{*}$ and $C l$ have been determined for four experiments. (Tests 46-101, 46-104, 47-101, 47-103, Reference $[3])$.

The range of Reynolds numbers investigated is (27,000 $65,000)$

The data obtained from the tests run at the Oak Ridge National Laboratory show heat balances lower than $95 \%$ f'or smaller values of Reynolds number and the present version of ENERGY I does not yet take this heat loss into account. The values $\varepsilon_{\mathrm{H}}^{*}=0.006$ and $\mathrm{Cl}=0$ lead to a good fit for the studied cases; they are included in the range of predictions $\varepsilon_{i \mathrm{i}}^{*}(0.0057$; $0.0036)$ CI $(0.0995 ; 0.2066)$. 
W11:1 Scale Test

This test presently run by the Westinghouse Electric Corporation consists of injecting a gaseous tracer in an air flow streaming through operation of a $217 \mathrm{pin}$ bundle. This experiment aims to simulate a sector of the FTR/CRBRP $217 \mathrm{p}$ in fuel assemoIy. The ENERGY I code has been converted into a form suitable for gaseous tracer concentration calculation. Two runs have already been done, using the actual geometrical parameters and Khan's prediction for the simulated bundle (Injection channels are a central channel and a wall channel)'. These predictions will have to be compared with the expertmental results to be published next quarter.

Karlsruhe Bundle

No available data from Karlsruhe has been recelved yet. Nevertheless a comparison of the predictions of both codes will be accomplished in Task (e). Three runs precedently done in Germany using the parameters of the Karlsruhe bundle as input data, have been very useful. Assuming that these runs represent the best fit with the experimental data, it is possible to determine the best parameters $\left(\varepsilon_{\dot{H}}^{*}\right.$ and $\left.C I\right)$ for ENERGY I.

(d) Generation of Input Data for Gridded Bundles (Frank Carré)

The study takes into account an axial variation of the dimensionless eddy diffusivity parameter $\varepsilon_{\text {f }}^{*}$ and tries to match the theoretical resuits with the experimentally measured temperatures in each of the following bundles:

- Swiss, Japanese bundles

-- Karlsruhe bundle

-- L.W.R. data (General Electric, Italtan)

Only very few data have already been published for heated pin or tracer injection tests in gridded bundles. The oniy available data for the Swiss or Japanese bundles are friction factor and pressure drop measurements.

Some data relative to the Karlsruhe $61-p$ in bundle allowed work to start in this area. [Reference 5] 
One type of grid (Honeycomb) has already been investigated and the value of $\varepsilon_{H}^{*}$ matching the exit temperatures has been determined. Unfortunately, temperature measurements at a single axial elevation do not allow to determine any axial variation of this parameter. If an exponential variation of

$$
\left.\varepsilon_{H}^{*}=\varepsilon_{H_{0}}^{*} \cdot e^{-\mu z}\right)
$$

Is assumed between two adjacent grids, only the average value

$$
\varepsilon_{H}^{*}=\varepsilon_{H_{O}}^{*} \cdot\left(\frac{I-e^{-\mu H}}{\mu^{H}}\right)
$$

seems to influence the exit temperature.

\section{(e) Comparison: MISTRAL II - ENERGY I (Frank Carré)}

The German thermohydraulic code MISTRAL II (Reference [6] uses two parameters ( $\mu$ and EF) as input data. The theoretical flow split is calculated the same way as in ENERGY I. It would be interesting to derive a relationship between those two sets of parameters and to express, analytically or numericaliy $\left(\varepsilon_{\mathrm{H}}^{*}\right.$ : Cl) in terms of $(\mu, E F)$. There are presently very few data avallable and the 5l-pins Karlsruhe bundle (Reference [7]) is the only one whlch has been studied by both codes. This comparison involves several runs of ENERGY I and MISTRAL. II with the same geometrical input data.

The study of the finite difference equations used by both programs and the comparison of the scheme of resolution, lead to an analytical relationship between the mixing parameters ( $\varepsilon$ and $\mu)$. Using the values of ( $\mu$ and EF) this relationship yields values of $\varepsilon_{H}^{*}$ in good agreement with the experimentally determined values and Khan's predictions.

The codes use a completely different approach to account for the swirl flow taking place in the wall channels, and the comparison of the intte difference equations valid in this region leacis to questionable results. Another point is that Khan's predictions have a wide range of uncertainty ( $+35 \%$ for $C I$ ) and that the runs of MISTRAL II from Germany are assumed to represent the best fit with the still unavailable Karlsruhe data. 
Besides the progress reported above, several modifications (conception of a new subroutine generating an automatic way of numbering the subchannels of an hexagonal, bundle) have improved the ENERGY I code and runs done with $2 \mathrm{~A}$ bundles data confirm the results previously obtained. A short translation of the report [6] has been done too.

Next quarter will be spent in further investigation of the three described steps:

*Analysis of Karlsruhe data as soon as they are available

*Analysis of gridded bundles data as soon as they are avallable.

* Determination of whether or not a good correlation between the parameters $\left(\varepsilon_{\mathrm{H}}^{*}, \mu, E F\right)$ can be analytically derived. 
TASK. II: SUBCHANNEL GEOMETRY (BARE RODS)

TASK IIA: Assessment of Available Data

No new data published in the literature which could be assessed this quarter.

TASK IIB: Exper1mental investigation (Joseph Kelly)

No significant new information was developed thís quarter. Data acquisition should be initiated next quarter.

TASK IIC: Experimental Subchannel Local Parameter Measurements (Laser Doppler Anemometer) (Pedro Carajilescov)

TASK IID: Analytic Model Development - Subchannel (Pedro Carajilescov)

During this quarter experimental measurements and analytic work by this investigator were completed. A summary (Appendix I) of this work follows (note the page numbers, figures and rererences have not been made sequeritial with this progress report since the summary has been prepared as a document which starids alore). A detailed topical report on this investigation will be issued next quarter. 
TASK III: LMFBR OUTLET PLENUM FLOW MIXING

TASK IIIA: Analytical and Experimental Investigation of Velocity and Temperature Fields

During the past quarter work has been carried on in preparation for velocity and temperature measurements in test cells similar to the LMFBR outlet plenum, and analytical work has been performed in anticipation of receipt of the code VARR-II [8], which will be used to predict the behavior of the experiments.

In the temperature measurement effort the primary interest is in developing an optical method of sensing temperature fluctuations, since it is recognized that mechanical means (thermocouples) are unattractive for this purpose, since they disturb the flow and since they have response-times ( $100 \mathrm{msec}$ ) greater than the time scale of the fluctuations (1-10 msec). The method being pursued uses a Mach-Zehnder interferometer, and is described more completely in. Appendix II. For the demonstration experiment the needed optical components (mirrors, beam,splitters, and mounts) have been obtained, along with the experimental mounting bed (two 12 in. Wlde flange beams). The experimental cell is currently being fabricated, along with some other minor equipment 1tems. It is expected that the experiment will be set up during the coming quarter.

In the velocity measurement effort the necessary equipment is assembled at MIT, but is currently being used in Subtasks I and II of this project. The test section for the velocity measurements (to be performed using the DISA Laser Doppler Anemometer) is shown in Fig. 16, and is currently being fabricated. It is expected that the experiment will be assembled, and cheakout tests performed during the coming quarter.

A major portion of the work in this task has been devoted to the analytical effort -- in an extensive literature survey, and in preparing modifications to the code VARR-II, which wili be implemented when it is received (anticipated in early April). The literature survey has been concerned with compiling a library of published zero-, one-, and two-equation turbulence models; and with understanding their differences and the tests to which they have been subjected. This survey is continuing, since the body of 11terature to be examined is large. 
Approval has been obtalned for the proprietary code VARR-II to. be provided to the project, and in anticipation of receiving it the code description manual has been used in planning required modifications. These involve adding a transient energy equation to be solved along with the equation set currently in the code (this is required if non-convective energy transport effects are to be accounted for in calculating local density), examining how the code must be modified in order to accommodate alternative turbulence models (in most new-turbulence equations will be required), and investigating what programming changes would be required to operate using the IBIT-360 computer of the MIT Laboratory for Nuclear Studies. (The code was written for a CDC system, and the major necessary modifications are expected to involve the input/output statements.) It js expected that the code will be recelved, and made operational at MIT during the coming quarter. 


\section{References}

[1] E.K. Novendstern, "Turbulent Flow Pressure Drop Model for Fuel Rod Assemblies Utilizing a Helical WireWrap Spacer System," Nuclear Engineering \& Design Vol. 22 (197.2)

[2] Klaus Rehme, "Pressure Drop Correlations for Fuel Element Spacers," Nuclear Technology, Vol. 17, January 1973

[3] Oak Ridge National Laboratory 5C Bundle data received from M.H. Fontana

[4]. W11:I Scale Test Description received from Mr. Mravaca

[5] H. Hoffman, E. Baumgartner, "Experimental Investigation of the Thermodynamic Behavior of Fast Breeder Reactor Fuel Elements with Different Spacer Types," IAEA-SM173120 .

[6] "MISTRAL-II Thermohydraulisher Mischstromungsalgirithmus fur Stabbundel," KFK-1605, Juni 1972.

[7] "Experimentelle Untersuchung zur Kuhlwittelquervermischung und zum Druckabfall im Stabbundel mit Wendelformigen Abstandhaltern, Einfluss der Ergebulsse auf die Auslegung ver Brernelementen Schueller Natrlum-gekuhlter Reaktoren," KFK-1843, Dezember 1973.

[8] J.L. Cook and P.I. Nakayoma, VARR-II, A Computer Program for Calculating Time-Dependent Turbulent Fluid Flows with Slight Density Variation, Science Applications, Inc., (August, 1974). 
TABLE I

MIXING EXPERIMENT PARAMETERS

\begin{tabular}{|c|c|c|c|c|c|}
\hline RUN & FLOWRATE' & $\begin{array}{l}\text { REYNOLDS } \\
\text { NUMBER } \\
\end{array}$ & $\begin{array}{c}\text { FLOW } \\
\text { REG IME } \\
\end{array}$ & $\begin{array}{c}\text { INJECTOR } \\
\text { AXIAL LOCATION } \\
\end{array}$ & $\begin{array}{c}\text { INJECTION. } \\
\text { CONCENTRATION } \\
\end{array}$ \\
\hline 1 & $55 \mathrm{GPN}$ & 5645 & I'urbulent & $I^{\prime \prime}-26 " *$ & $4 \%$ \\
\hline 2 & $10 \mathrm{GPM}$ & 1026 & Laminar & $I^{\prime \prime}-26^{\prime \prime} *$ & $4 \%:$ \\
\hline 3 & $5-1156$ GPM** & $513-11804$ & $\begin{array}{l}\text { Laminar- } \\
\text { Turbulent }\end{array}$ & $12 "$ & $4 \%$ \\
\hline 4 & 5-1156 GPM** & $513-1.1804$ & $\begin{array}{l}\text { Laminar- } \\
\text { Turbulent }\end{array}$ & $24 "$ & $4 \%$ \\
\hline
\end{tabular}

*Data takes at 50 different axial locations.

* Data takes at 10 different flowrates 
$-18-$

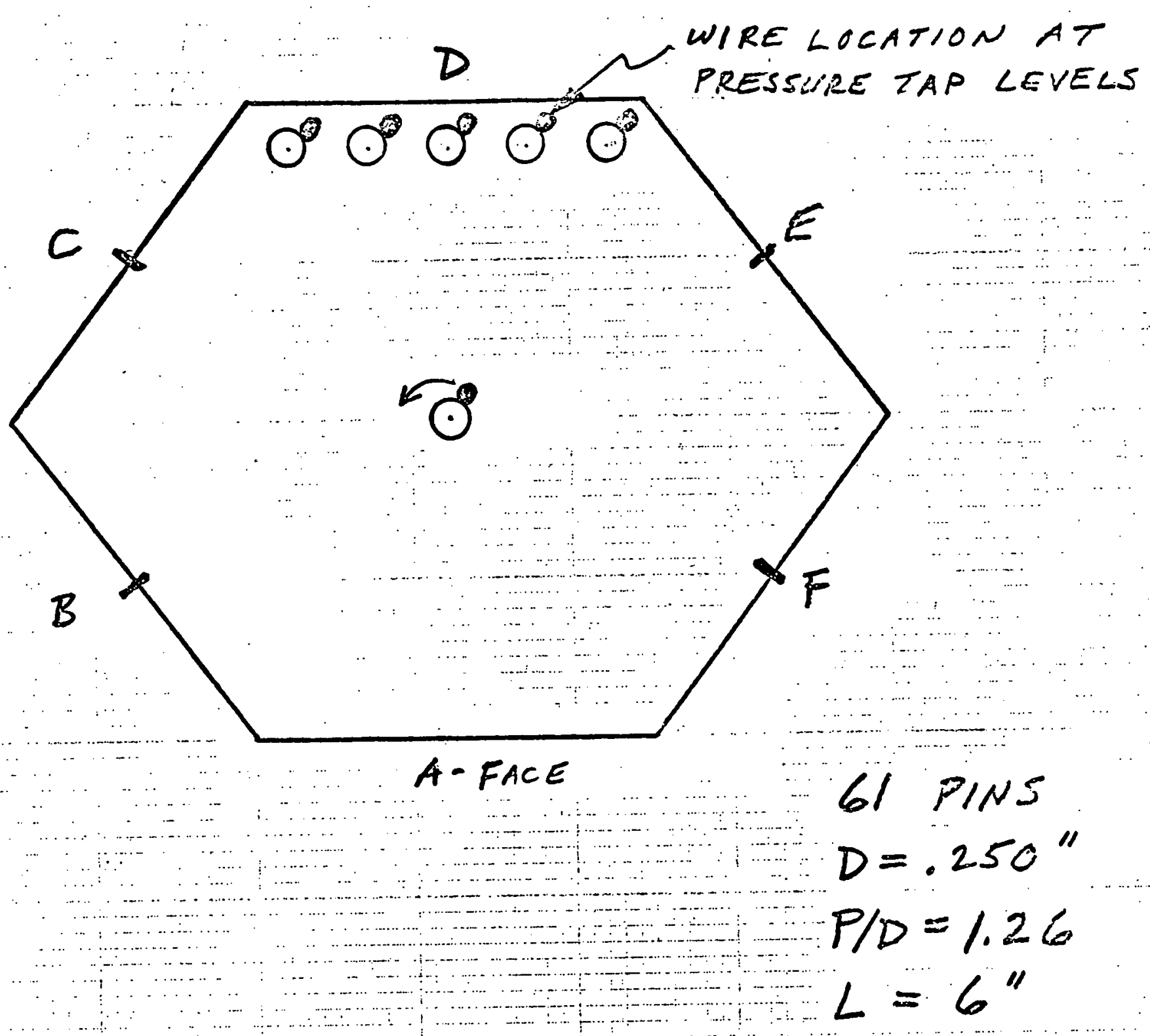

PRESSURE TAPS LOCATED AT FROM EXIT AND 3 'FROM EXIT. TAPS LOCATED AT CENTER OF FACES, 4 SIDES ONLY.

FIGURE 1

PRESSURE TAP LOCATIONS 


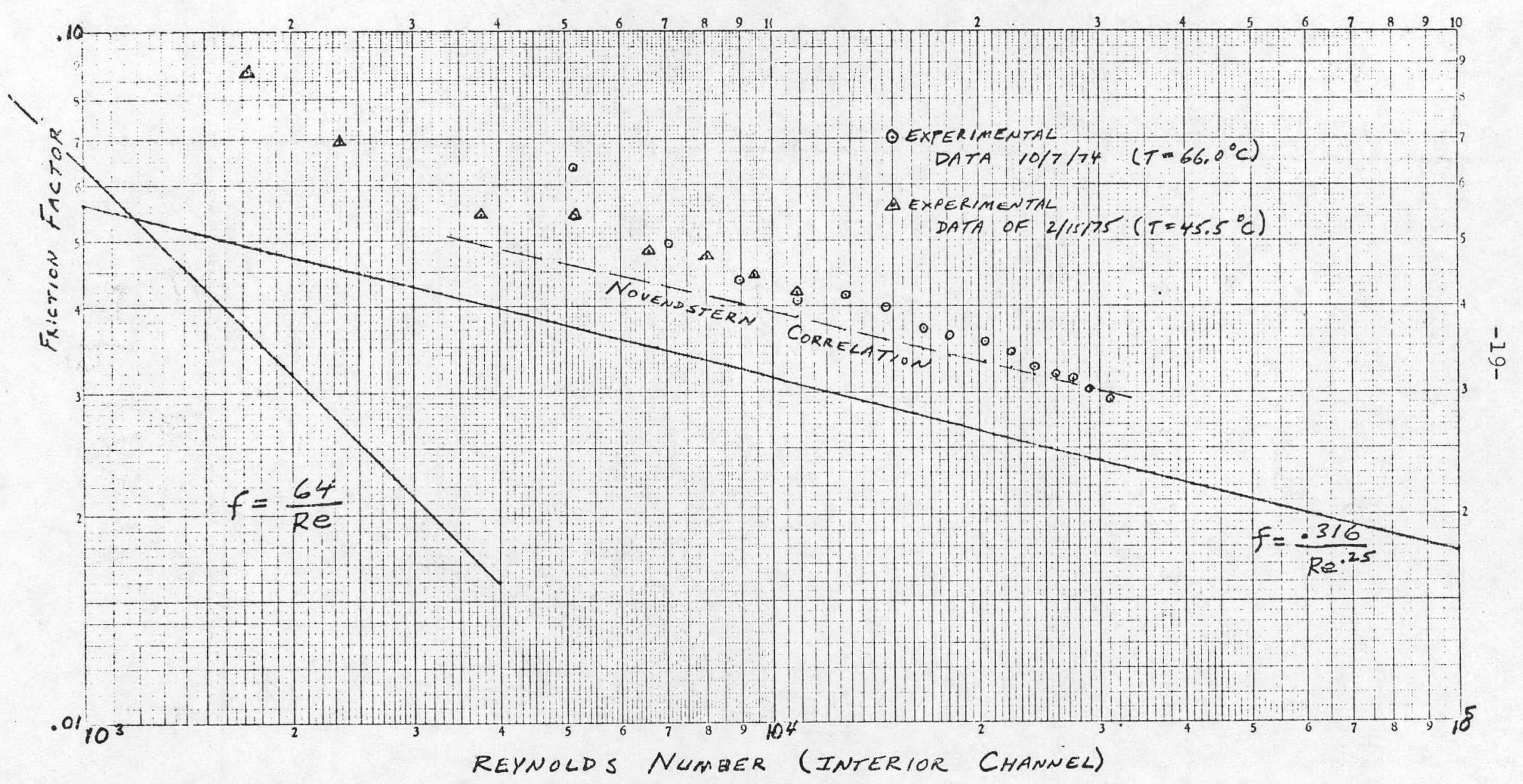

FICURE 2- FRICTOON FACTOR VS. REINOLDS NUMSER RELATION 












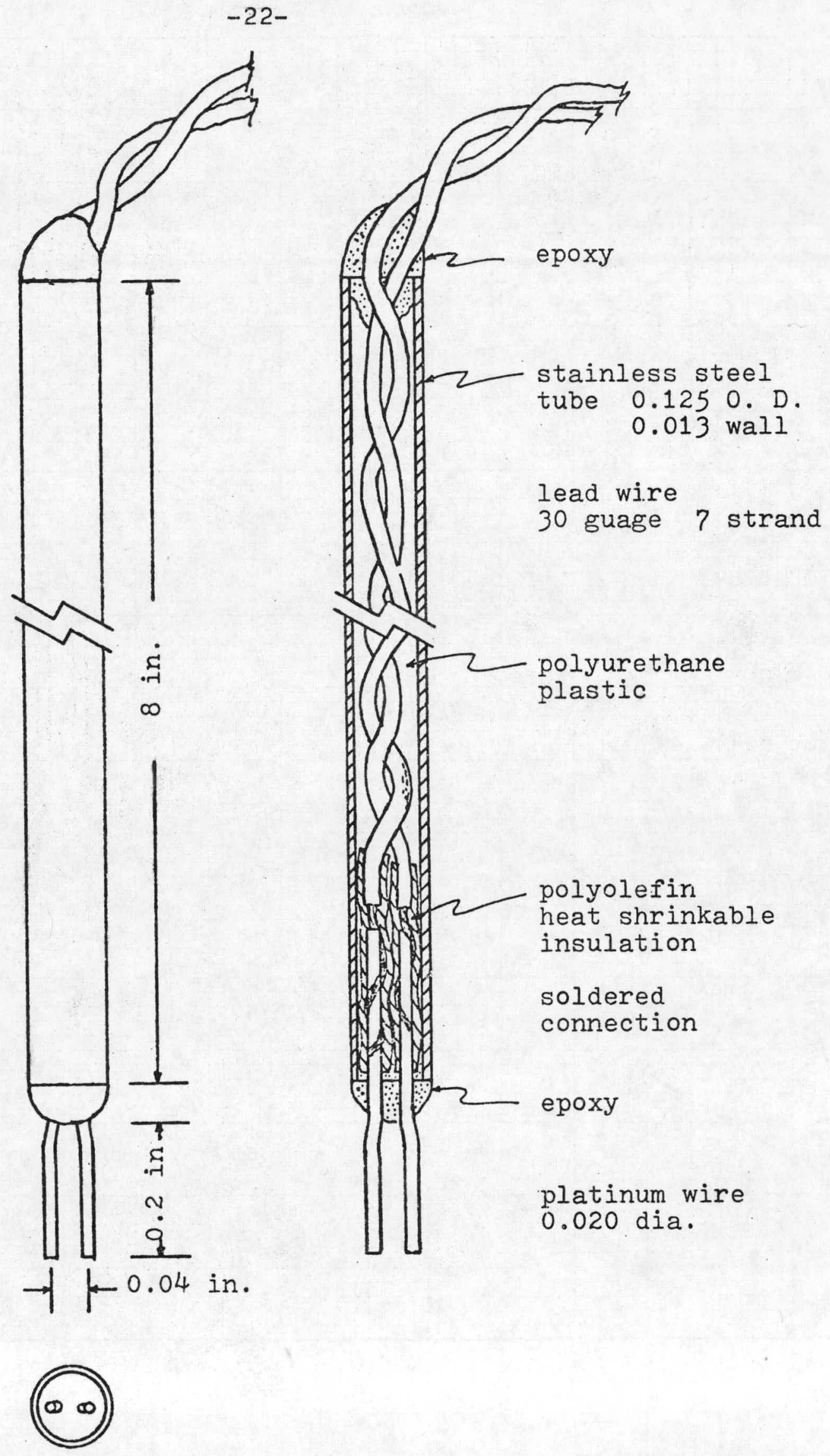

Probe Construction

Figure 5 


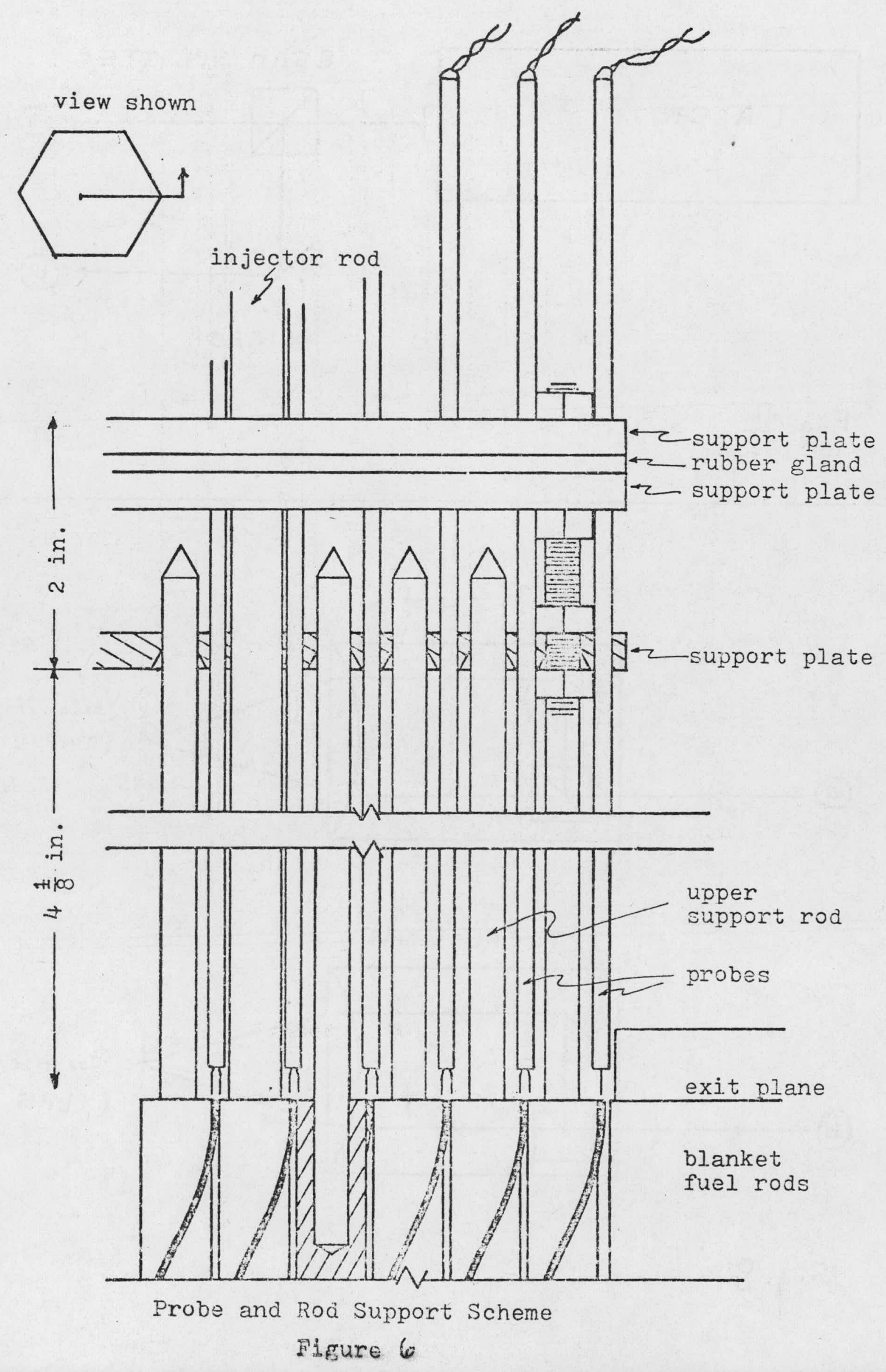


$-24-$

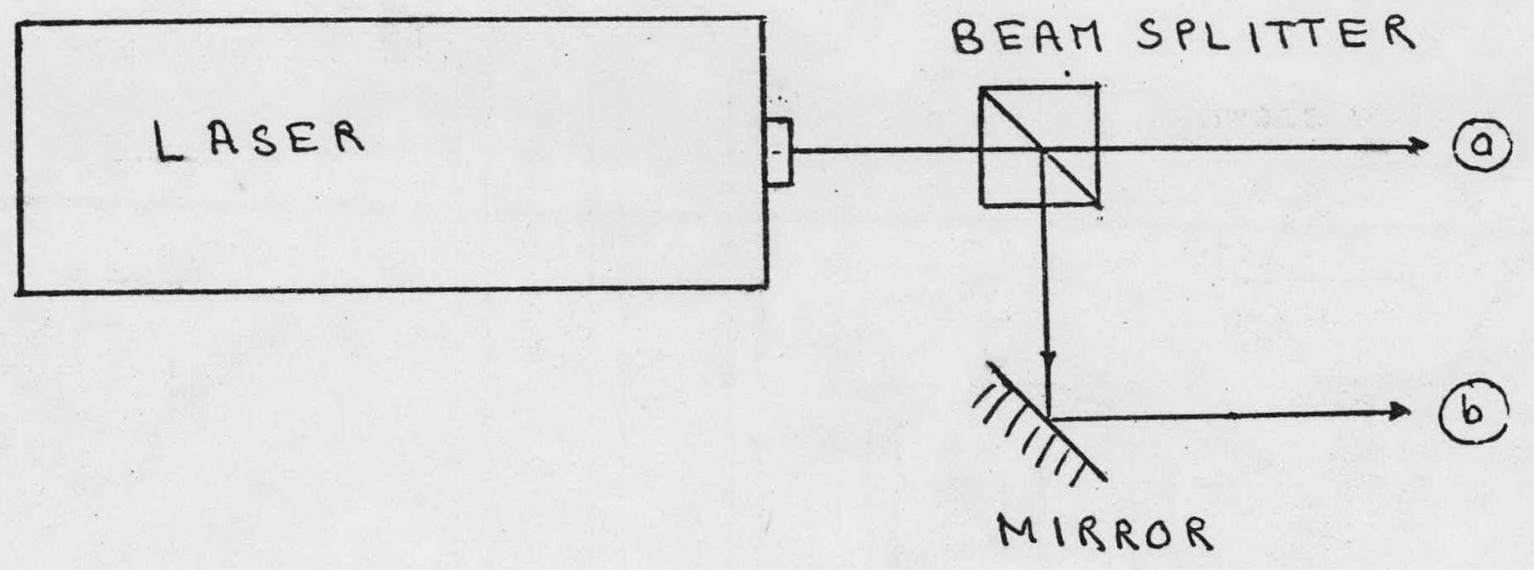

Fig. I

(a)

OPTICAL UNIT
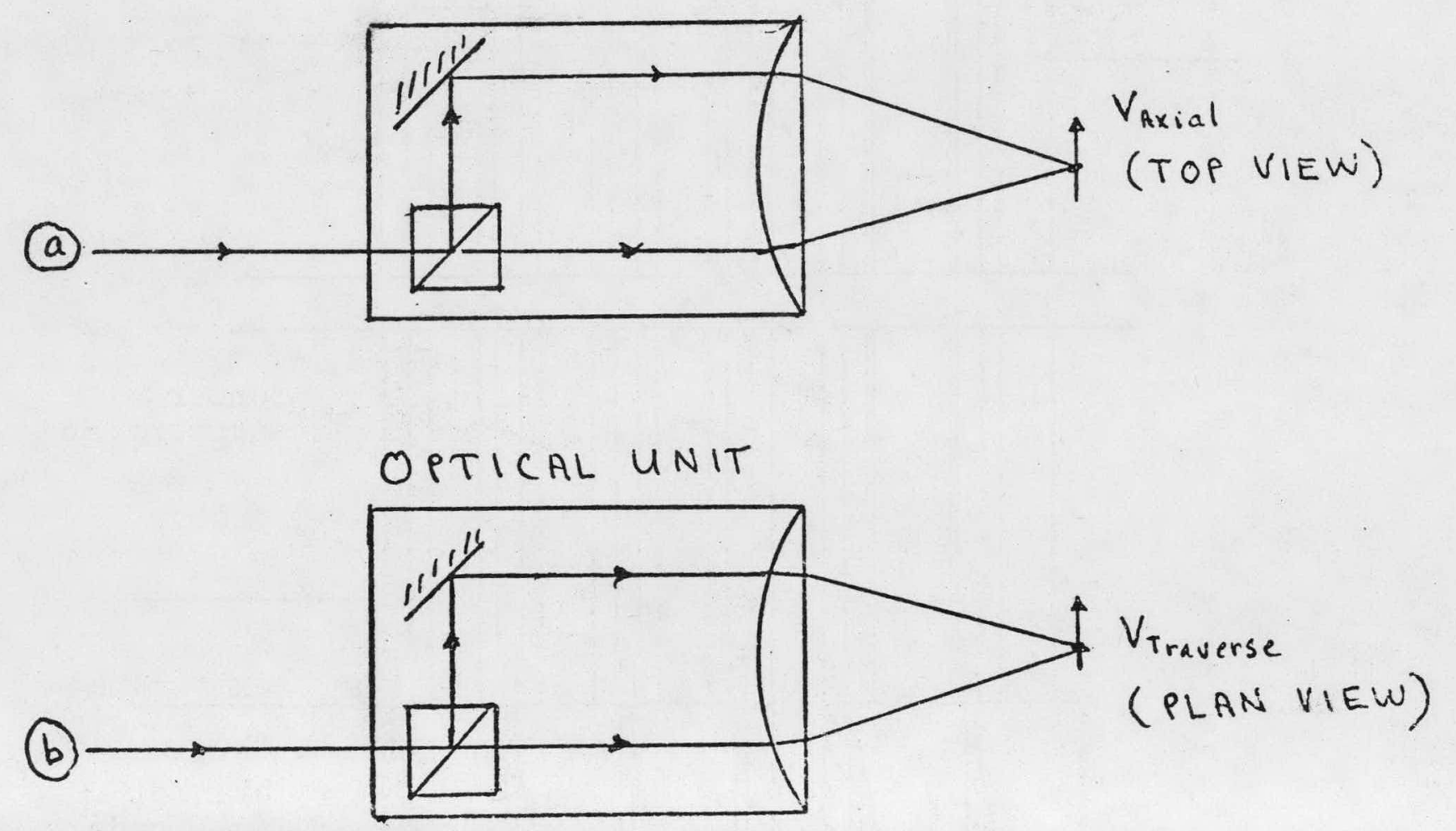

Fig. 8 
$-25-$
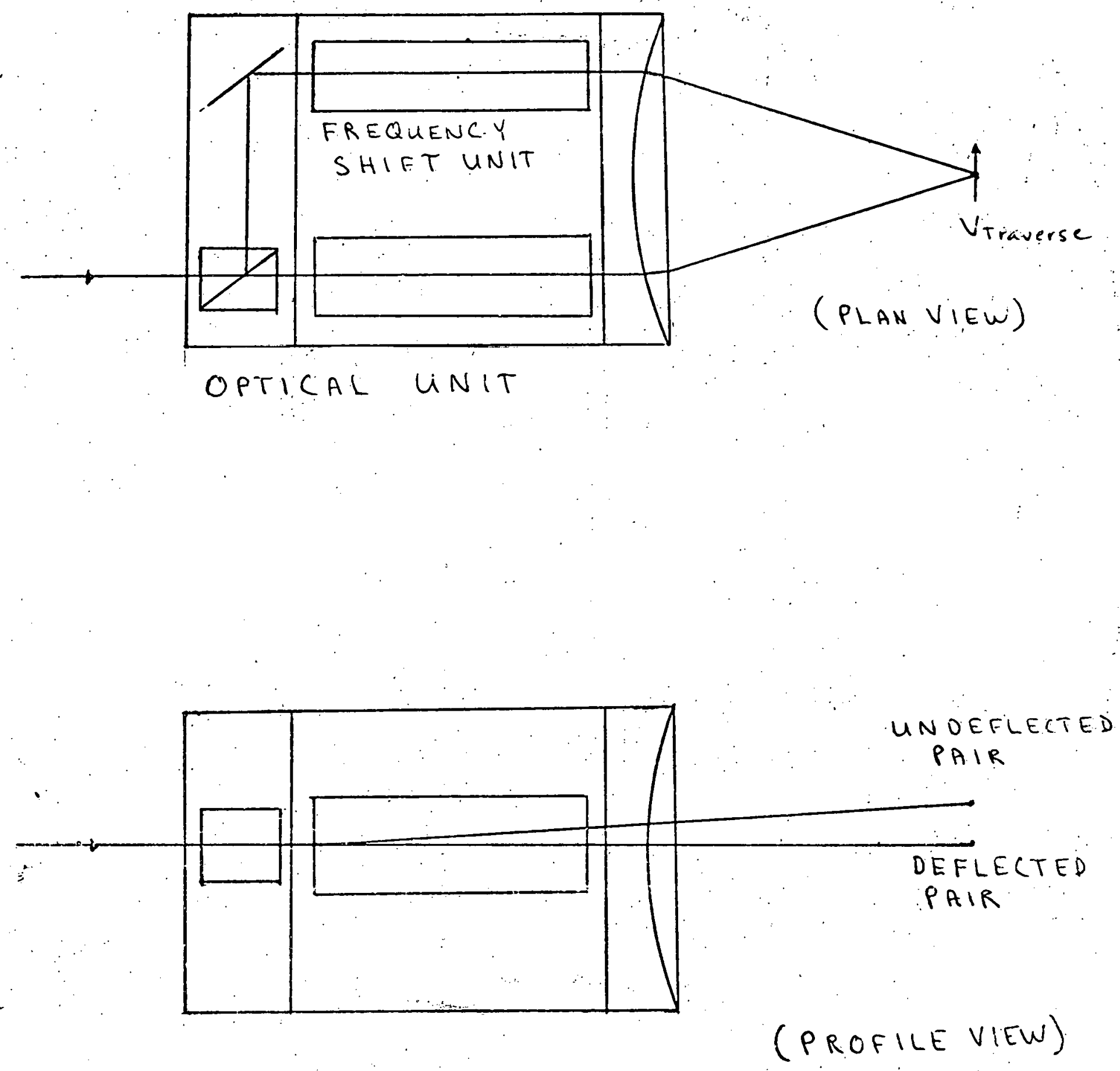

Fig. 9 
$-26-$

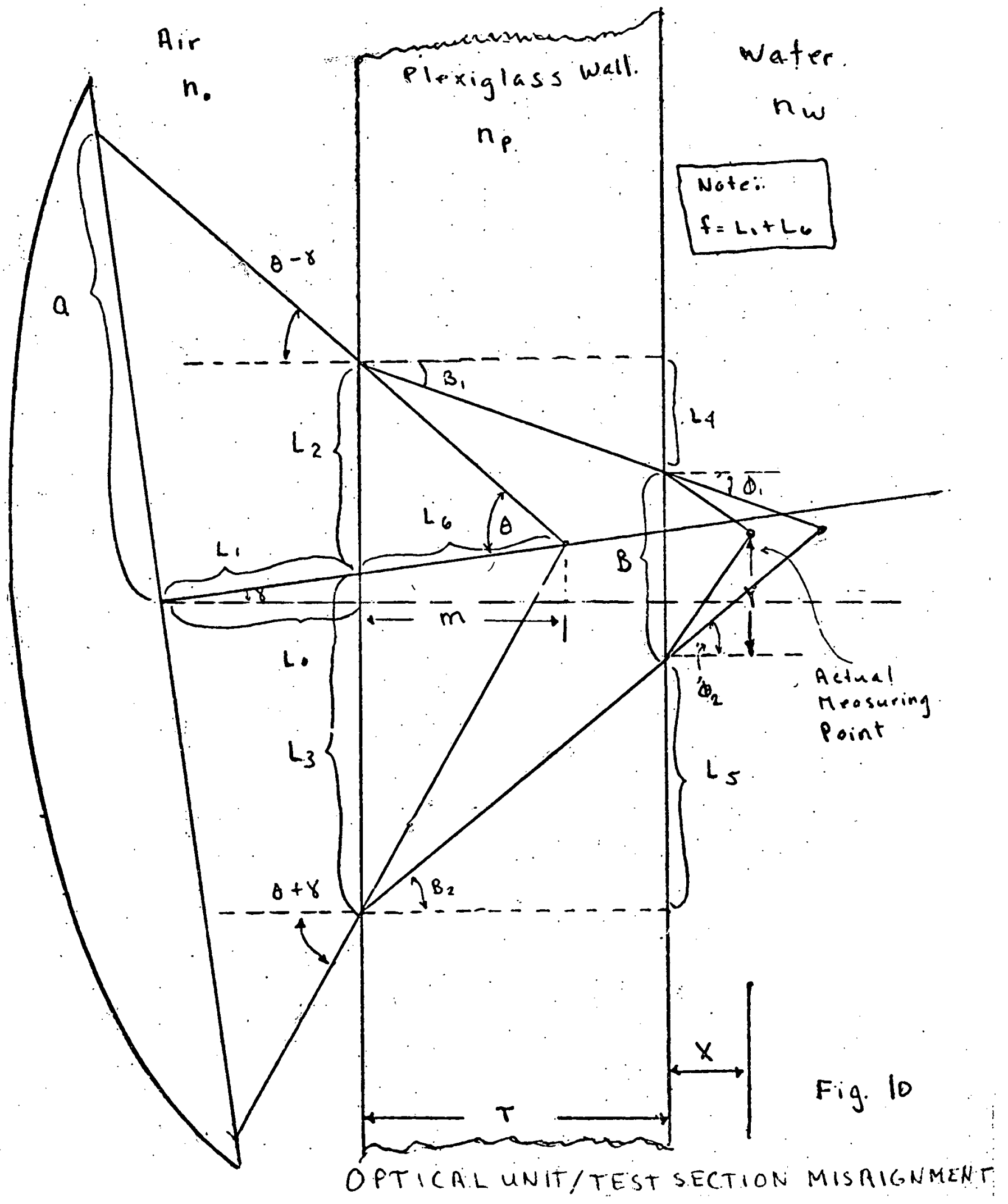




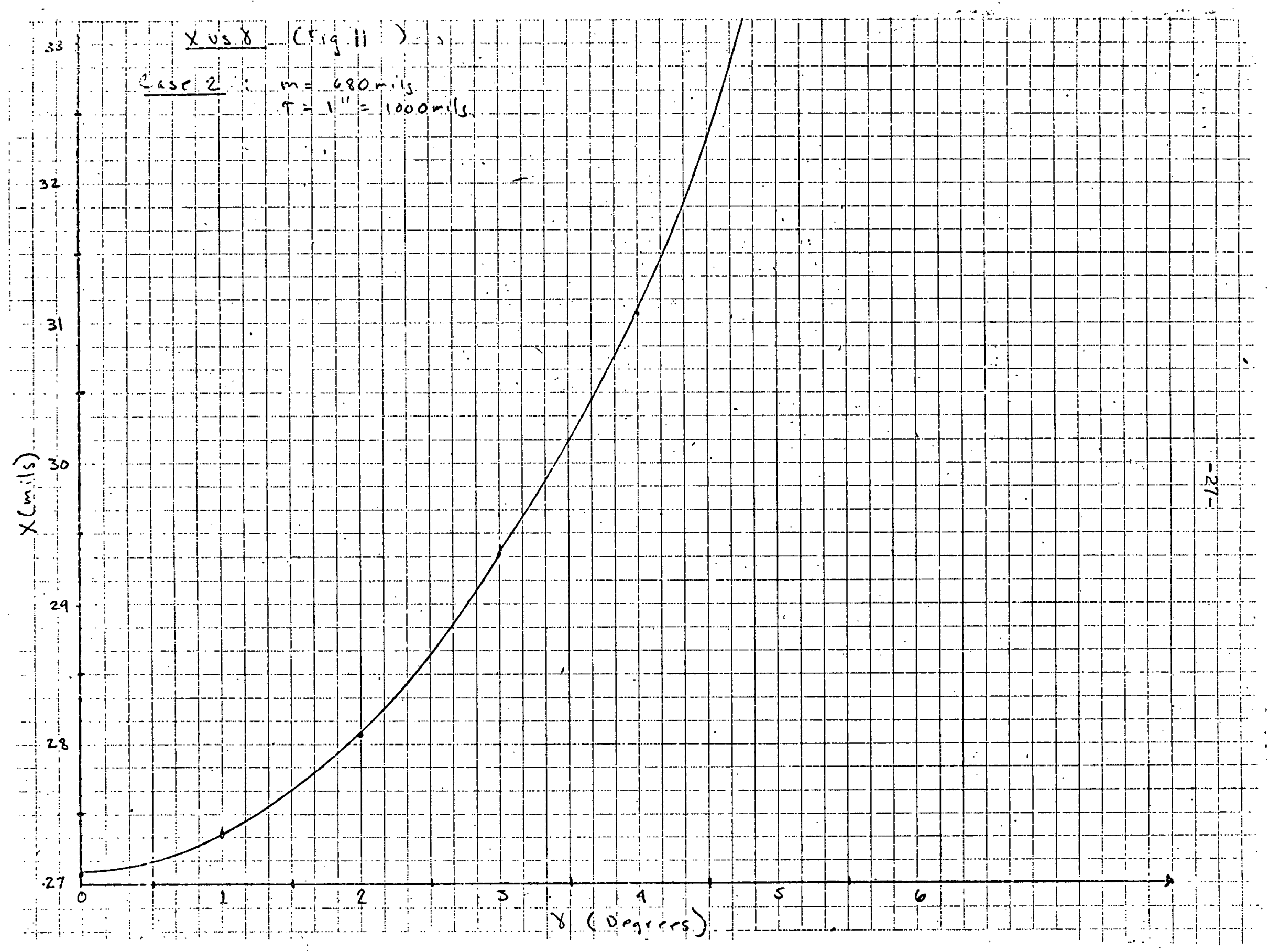




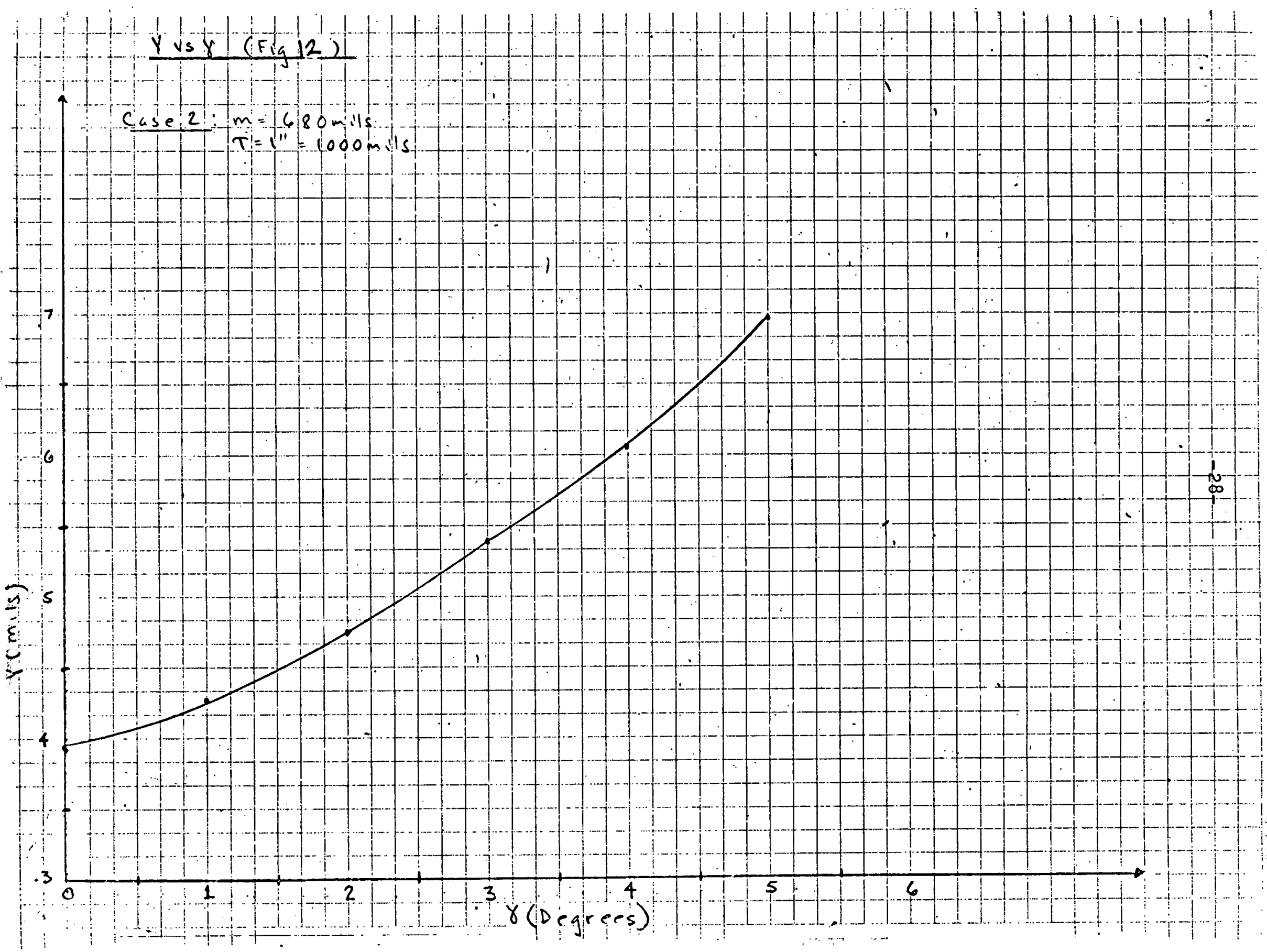


$-29-$

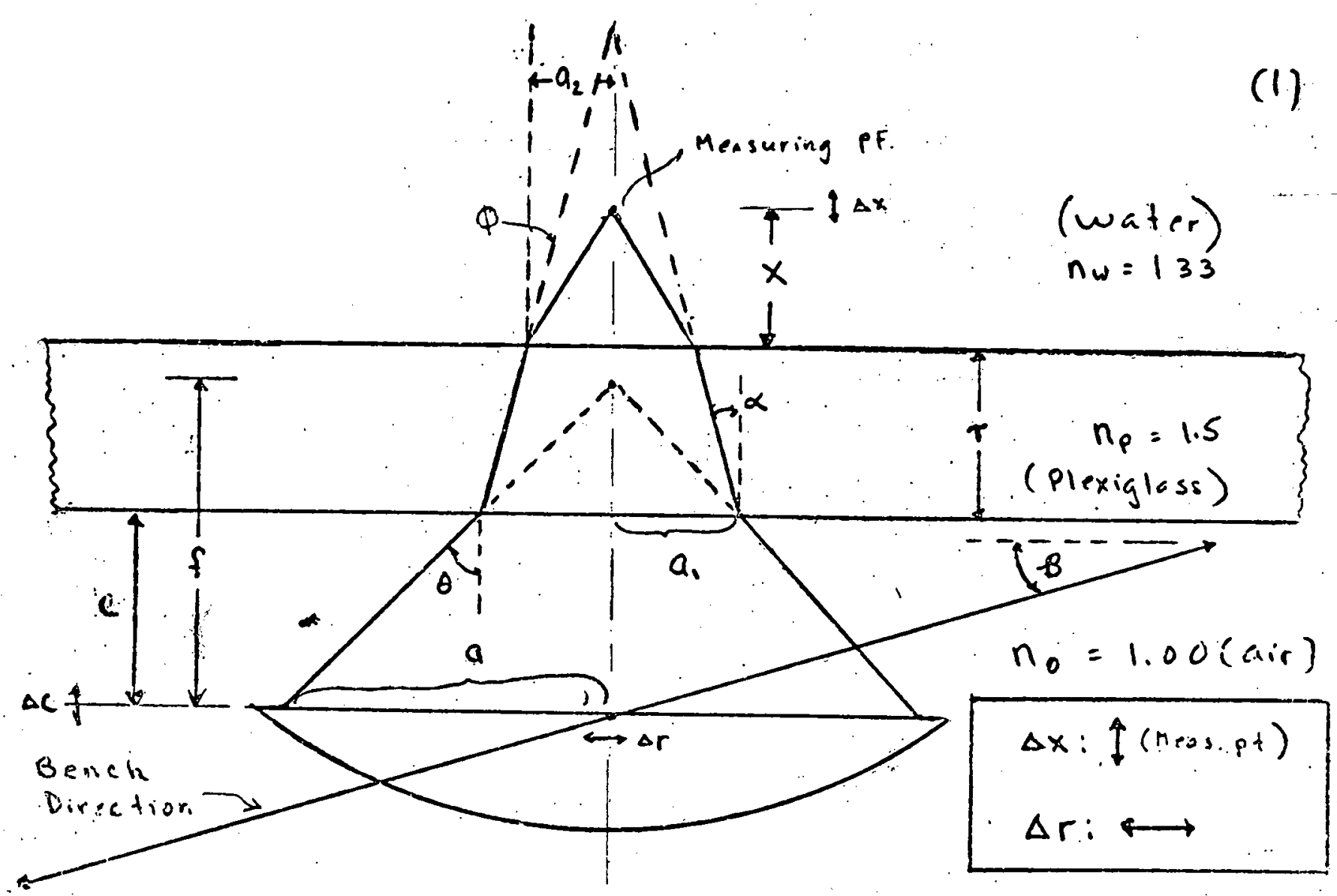

Fig 13

Optical Bench fest Section

Misalignment model 


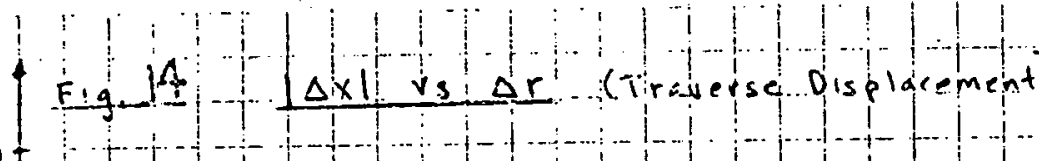

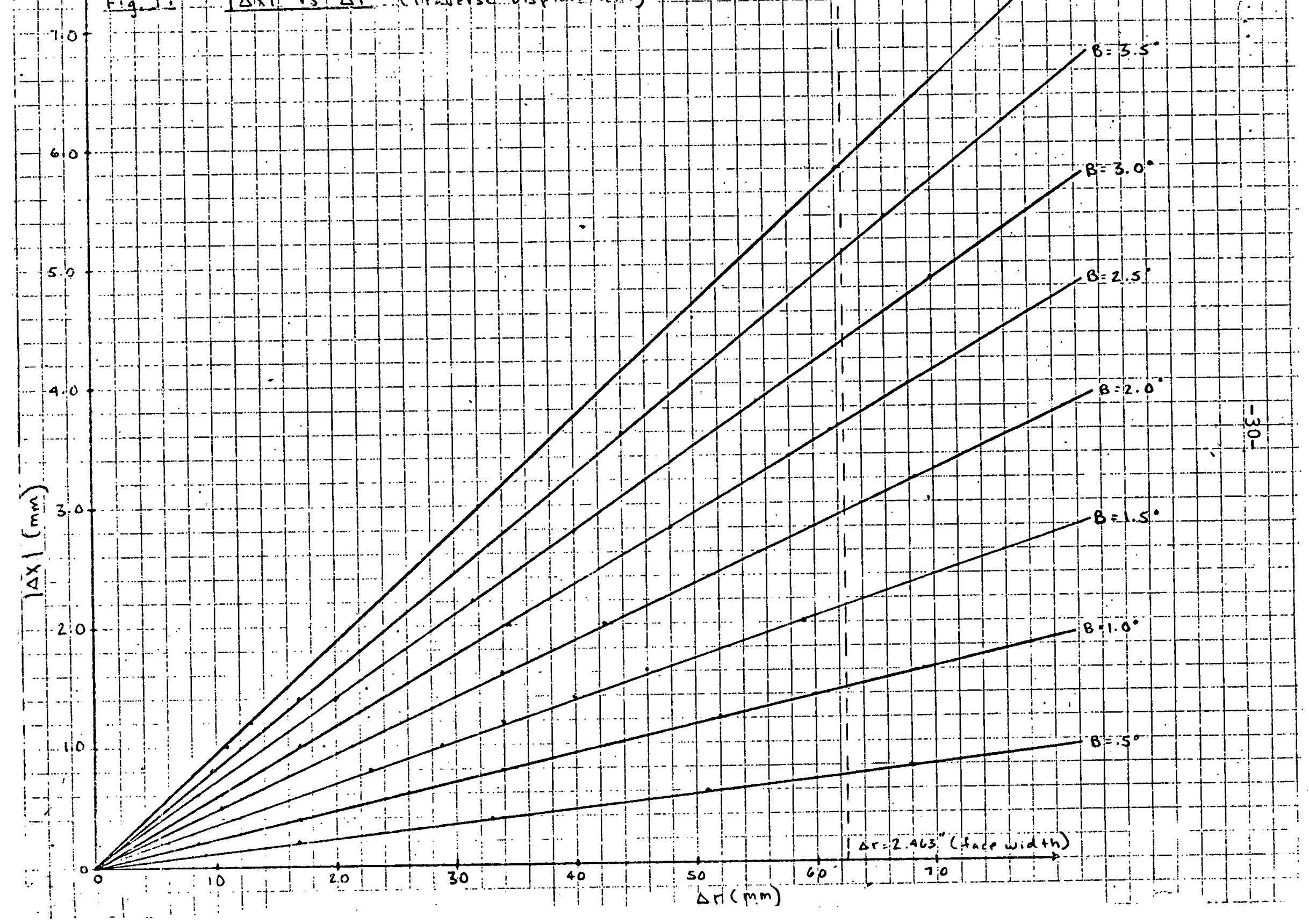




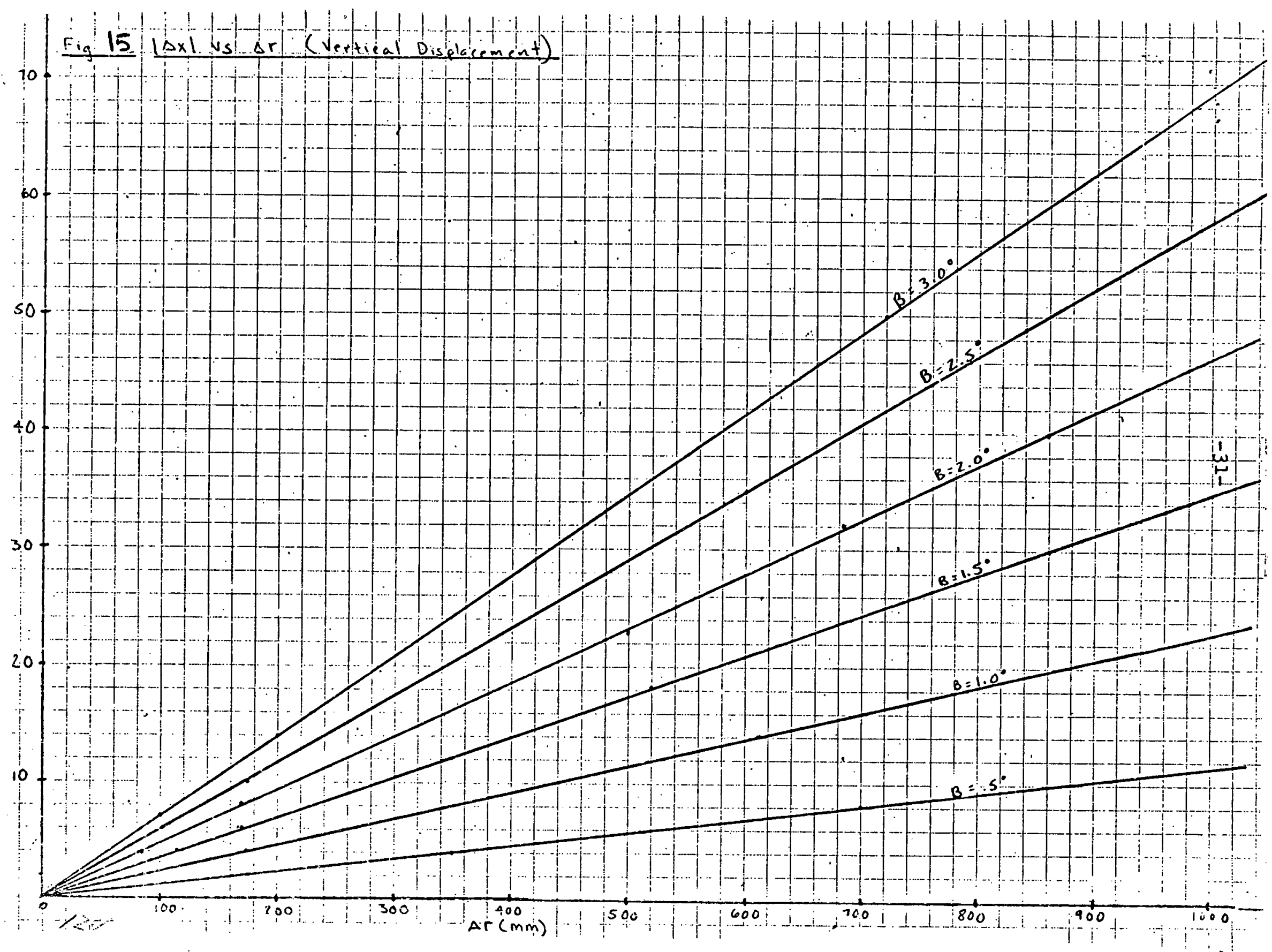




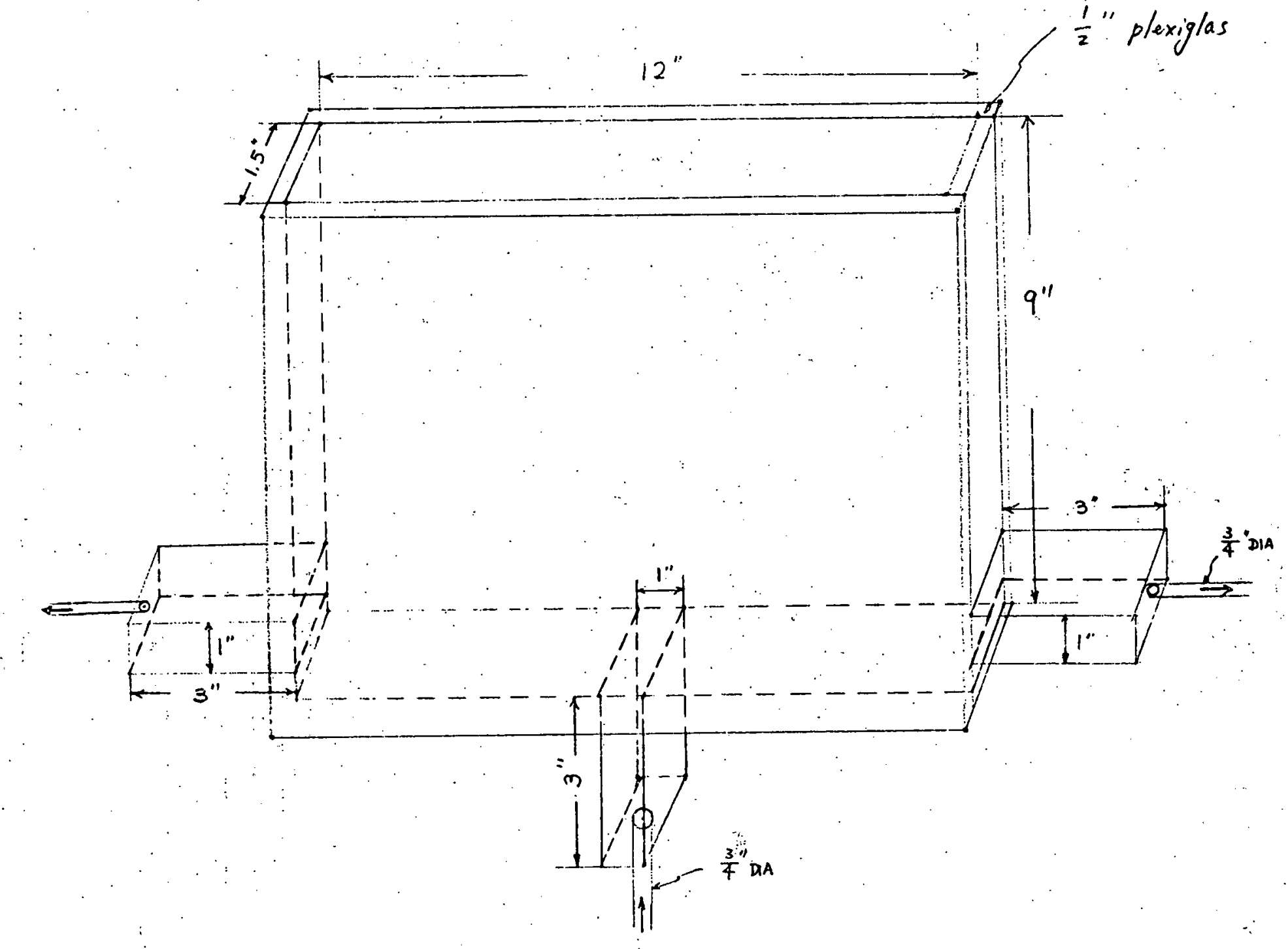

$\stackrel{\dot{\omega}}{i}$

Fig. 16 Velocity Measurement Test Cell 